\title{
ARTICLE
}

\section{The Application of HTP Projection Test in the Psychological Survey of Tibetan and Han College Students}

\section{Hua $\mathrm{Xu}^{1 *}$ Qiyu Liu ${ }^{2}$ Deji Yuzhen}

1. Xizang Minzu University, Xianyang, Shaanxi, 712000, China

2. No.3 Middle School, Wujiaqu, Xinjiang, Urumqi, Xinjiang, 831300, China

3. Lhasa Police Force, Lhasa, Tibet, 850000, China

\begin{tabular}{l}
\hline ARTICLE INFO \\
\hline Article history \\
Received: 20 February 2020 \\
Revised: 27 February 2020 \\
Accepted: 9 April 2020 \\
Published Online: 16 April 2020 \\
\hline
\end{tabular}

\section{Keywords:}

Psychological survey

The HTP test

Tibetan College Students

\begin{abstract}
The projective test is not only helpful to find the potential psychological crisis, but also to overcome the language barrier and make up for the deficiency of the questionnaire test to a certain extent.In this study, 403 college students (205 Tibetan students and 198 Han students) from a national college were selected to test their mental health with Symptom Checklist-90 (SCL-90) and House-Tree-Person test (HTP).By comparing the results of questionnaire test and drawing projection test, it is found that SCL-90 and HTP test are significantly related to the positive screening results of four factors: Somatization, Depression, Anxiety and Phobic Anxiety. Both HTP test and SCL-90 test results show that the scores of Somatization, Depression, Anxiety and Phobic Anxiety of Tibetan and Han college students were significantly different; the scores of Anxiety and Phobic Anxiety of different gender college students were significantly different. Using HTP test as a supplementary test of questionnaire test can effectively improve the accuracy of screening.
\end{abstract}

\section{Introduction}

$\mathrm{I}$ $\mathrm{n}$ recent years, with people's attention to mental health, college students in China are required to carry out mental health survey after enrollment. First of all, mental health survey can screen out students who may have mental problems and provide direction for the next intervention of the school. Secondly, mental health survey can play a role in the publicity and popularization of mental health knowledge, so that students can understand the importance of mental health. Thirdly, we can establish mental files for college students through mental health survey, so as to fully understand the mental health status of college students, and carry out targeted education and

\section{*Corresponding Author:}

Hua Xu,

Female, bachelor's degree, professional title, elementary level;

Research direction: application of drawing psychology in psychological education of Tibetan college students;

E-mail:312089098@qq.com

Fund Project:

This paper is one of a series of research results of the soft science research project "Application of Painting Art Therapy in the Mental Health Education of Tibetan College Students" (a key project at the provincial level; Project Approval No.: RK20180010) of the department of science and technology of Tibet Autonomous Region. 
counseling based on this ${ }^{[1]}$.

At present, the mental health survey of college students in China mostly uses questionnaire tests, such as UPI, 16PF and SCL-90, which are the most commonly used tests at present. Although the scores and analysis of these tests are relatively mature and objective, there are still problems such as students deliberately covering up and randomly answering. Some students may also be unable to fully understand the meaning of the question in a short period of time, the computer operation is not skilled, and the emotional tension affects the psychological state of the test and then interferes with the test results, which is very common among Tibetan college students. Through observation, the author found that the same psychological test, Tibetan college students completed the test time is about 1.5 times as long as Han college students. In the follow-up psychological interview, some Tibetan students told the teacher that the reason for the wrong answer was that they did not understand the meaning of the question. Tibetan students' mother tongue is Tibetan, so it is really difficult for them to complete the psychological test in a short time. In order to solve this problem, this study uses the combination of questionnaire test and HTP test to investigate the mental health of college students. HTP test method is simple, easy to implement, novel, easy to understand, and students are also very cooperative in the test ${ }^{[2]}$.

\section{Research Objects and Methods}

\subsection{Research Objects}

A total of 403 valid questionnaires (198 of Han nationality, 205 of Tibetan nationality, 177 of boys and 226 of girls) were collected from 420 college students randomly. The subjects were aged between 16-23 years old.

\subsection{Research Methods}

\subsubsection{Test Method}

in order to test the screening effect of HTP test, the most widely used Symptom Checklist-90 (SCL-90) in college psychological survey was selected as the control test to test the subjects in groups. HTP test was scored according to The Manual of Painting Psychoanalysis and Psychotherapy (Second Edition) ${ }^{[1]}$, and SCL-90 test was scored and counted by computer.

\subsubsection{Test Implementation}

Specific steps: HTP test first. After the completion of the painting test, the SCL-90 questionnaire will be issued for testing.

Notes: (1) In order to avoid mutual influence during the test, the subjects should sit separately to avoid seeing other people's questionnaires; (2) Provide the subjects with pencils of the same model and a piece of A4 paper (if the subjects want the second one, the first one should be handed in, recorded and filed; 3) Keep the classroom quiet, the cell phone silent, and the test time is not disturbed at will.

Instruction: "Please lay A4 paper horizontally and draw houses, trees and people on it. To include these three things, other things can be added at will. The time is 12 minutes. Please raise your hand for help. " ${ }^{[1,3]}$

\subsubsection{Classification and Coding}

Classification: Through literature search and data search, the painting features corresponding to 9 factors in the SCL-90 test are sorted out, and the classification items and coding standards are determined according to the existing feature interpretation system. (Table 1)

Table 1. Painting Characteristics and Corresponding Psychological Symptom Factors

\begin{tabular}{|c|c|}
\hline Factor & Painting features ${ }^{[1-6]}$ \\
\hline$\underline{\text { SOM }}$ & $\begin{array}{l}\text { The picture is too small, the eyebrows are sparse, the ears are } \\
\text { small, the neck is long and thin, the organ is protruding, the } \\
\text { trunk is blackened, etc }\end{array}$ \\
\hline$\underline{\mathrm{O}-\mathrm{C}}$ & $\begin{array}{c}\text { In the middle of the drawing paper, the lines are repeatedly } \\
\text { sketched, the picture is in a straight line, too symmetrical, the } \\
\text { description is meticulous, the cobblestone road, the branches are } \\
\text { clear, the hair is described in detail, etc }\end{array}$ \\
\hline$\underline{\text { INT }}$ & $\begin{array}{l}\text { There are many sharp points, sharp corners on the roof, black- } \\
\text { ened windows, no doors and windows, high threshold, very high } \\
\text { windows, fences or ditches, single line trunk, single line branches, } \\
\text { small figures, abstract figures, missing facial features, etc }\end{array}$ \\
\hline$\underline{\text { DEP }}$ & $\begin{array}{c}\text { The picture is too small, under the paper, with light lines, too } \\
\text { separate picture, monotonous composition, shadow, small house, } \\
\text { blackened doors and windows, closed doors and windows, sag- } \\
\text { ging branches, dead trees, fallen leaves, etc }\end{array}$ \\
\hline$\underline{\text { ANX }}$ & $\begin{array}{l}\text { The picture is too large, too many short lines, the picture is } \\
\text { messy, blackened, highlighted, shadowed, scratched, the roof } \\
\text { is too large, thick smoke, disordered tree crown, the body of } \\
\text { the character is blackened, the hair is thick and blackened, the } \\
\text { emphasis is applied to some place, etc }\end{array}$ \\
\hline$\underline{\mathrm{HOS}}$ & $\begin{array}{c}\text { The picture is too large, above the paper, simple, with many } \\
\text { sharp points, top view, sharp roof, fence, sharp Branch, figure on } \\
\text { the back, big head, emphasis on face, raised eyebrows, big nose, } \\
\text { sharp nose, etc }\end{array}$ \\
\hline PHOB & $\begin{array}{l}\text { At the bottom of the paper, trembling lines, light strokes, empha- } \\
\text { sizing the baseline, no baseline of the house, multiple locks of } \\
\text { doors and windows, small figures, fuzzy faces, etc }\end{array}$ \\
\hline$\underline{\text { PAR }}$ & $\begin{array}{l}\text { Window lock, quadrangle crown, palm crown, huge crown } \\
\text { ratio, trunk of electric pole, short trunk, too large figure, straight } \\
\text { eyebrows, big ears, no ears, thick short neck, upright body, etc }\end{array}$ \\
\hline$\underline{\text { PSY }}$ & $\begin{array}{l}\text { The picture is not harmonious, the picture has no sense of dis- } \\
\text { tance and proximity, lacks the theme,too heavy or too light pen } \\
\text { strength, the whole is monotonous, the lines are disordered, the } \\
\text { house perspective, no roof, clothes perspective, viscera painting, } \\
\text { etc }\end{array}$ \\
\hline
\end{tabular}

Coding: 0,1 score is used, binary variable index is used for coding. If there are painting features that are consistent 
with the coding items in the painting, 1 score will be given, otherwise 0 score will be given. The coding personnel are all college students with relevant training, and the raters are professional teachers with relevant psychological qualification certificates or teachers trained in professional painting psychological analysis.

\section{Results}

\subsection{Correlation between HTP Test and SCL-90 Scores}

It can be seen from table 2 that there are 9 different factors in the SCL-90 of Somatization, Obsessive-Compulsive, Interpersonal Sensitivity, Depression, Anxiety, Hostility, Phobic Anxiety, Paranoid Ideation and Psychoticism, all of which have significant positive correlation. HTP test results and SCL-90 there was significant cor- relation among the four factors of the scale, which were obsessive-compulsive factor $(r=0.177, p<0.05)$, depression factor $(r=0.119, p<0.05)$, hostility factor $(r=0.233$, $\mathrm{p}<0.05)$ and psychotic factor $(\mathrm{r}=0.205, \mathrm{p}<0.05)$.

\subsection{Comparison of the Average Scores of HTP Test and SCL-90 Test between Tibetan and Han College Students}

From Table 3 above, it can be seen that HTP test and SCL-90 test results show that Tibetan and Han college students have significant differences in scores on four factors (Somatization, Depression, Anxiety, Phobic Anxiety). In addition, SCL-90 test results show that college students of different nationalities have significant differences in scores on two factors of Obsessive-Compulsive and Hostility, $\mathrm{p}<0.05$.

Table 2. Correlation between HTP Test and SCL-90 Test Scores of College Students

\begin{tabular}{|c|c|c|c|c|c|c|c|c|c|c|}
\hline Variable & $\mathbf{H T P}$ & $\underline{\mathbf{S O M}}$ & $\underline{\mathbf{O}-\mathbf{C}}$ & $\underline{\mathbf{I N T}}$ & $\underline{\mathbf{D E P}}$ & $\underline{\mathbf{A N X}}$ & $\underline{\text { HOS }}$ & $\underline{\mathbf{P H O B}}$ & $\underline{\text { PAR }}$ & $\underline{\mathbf{P S Y}}$ \\
\hline HTP & 1 & & & & & & & & \\
\hline$\underline{\mathbf{S O M}}$ & 0.049 & 1 & & & & & & & \\
\hline$\underline{\mathbf{O}-\mathbf{C}}$ & $0.177^{*}$ & $0.662^{* *}$ & 1 & & & & & & \\
\hline$\underline{\mathbf{I N T}}$ & 0.039 & $0.642^{* *}$ & $0.757^{* *}$ & 1 & & & & & & \\
\hline$\underline{\mathbf{D E P}}$ & $0.119^{*}$ & $0.694^{* *}$ & $0.770^{* *}$ & $0.818^{* *}$ & 1 & & & & & \\
\hline$\underline{\mathbf{A N X}}$ & 0.029 & $0.726^{* *}$ & $0.774^{* *}$ & $0.771^{* *}$ & $0.818^{* *}$ & 1 & & & & \\
\hline$\underline{\mathbf{H O S}}$ & $0.233^{*}$ & $0.625^{* *}$ & $0.612^{* *}$ & $0.625^{* *}$ & $0.650^{* *}$ & $0.690^{* *}$ & 1 & & & \\
\hline$\underline{\mathbf{P H O B}}$ & 0.083 & $0.552^{* *}$ & $0.634^{* *}$ & $0.671^{* *}$ & $0.695^{* *}$ & $0.720^{* *}$ & $0.471^{* *}$ & 1 & & \\
\hline$\underline{\mathbf{P A R}}$ & 0.032 & $0.658^{* *}$ & $0.680^{* *}$ & $0.782^{* *}$ & $0.773^{* *}$ & $0.741^{* *}$ & $0.692^{* *}$ & $0.570^{* *}$ & 1 & \\
\hline$\underline{\mathbf{P S Y}}$ & $0.205^{*}$ & $0.663^{* *}$ & $0.716^{* *}$ & $0.745^{* *}$ & $0.771^{* *}$ & $0.791^{* *}$ & $0.656^{* *}$ & $0.632^{* *}$ & $0.734^{* *}$ & 1 \\
\hline
\end{tabular}

Notes: ${ }^{*} \mathrm{p}<0.05, * * \mathrm{p}<0.01,{ }^{*} * \mathrm{p}<0.001$; SOM: Somatization, O-C: Obsessive-Compulsive, INT: Interpersonal Sensitivity, DEP: Depression, ANX: Anxiety, HOS: Hostility, PHOB: Phobic Anxiety, PAR: Paranoid Ideation, PSY: Psychoticism.

Table 3. Comparison of Average Scores of HTP Test and SCL-90 test between Tibetan and Han College Students

\begin{tabular}{|c|c|c|c|c|c|c|c|c|}
\hline \multirow{2}{*}{ Factor } & \multicolumn{5}{|c|}{ HTP test } & \multicolumn{4}{c|}{ SCL-90 test } \\
\cline { 2 - 10 } & $\begin{array}{c}\text { Tibetan college } \\
\text { Students(n=205) }\end{array}$ & $\begin{array}{c}\text { Han College } \\
\text { Students(n=198) }\end{array}$ & $\mathbf{t}$ & $\mathbf{P}$ & $\begin{array}{c}\text { Tibetan College } \\
\text { Students } \\
(\mathrm{n}=205)\end{array}$ & $\begin{array}{c}\text { Han College } \\
\text { Students } \\
(\mathrm{n}=198)\end{array}$ & $\mathbf{t}$ & $\mathbf{P}$ \\
\hline$\underline{\text { SOM }}$ & $11.65 \pm 7.37$ & $8.56 \pm 3.66$ & 5.357 & $\mathbf{0 . 0 0 0}$ & $1.62 \pm 0.49$ & $1.5 \pm 0.41$ & 2.652 & $\mathbf{0 . 0 0 8}$ \\
\hline$\underline{\mathbf{O - C}}$ & $7.36 \pm 2.16$ & $7.15 \pm 2.08$ & 0.969 & 0.333 & $1.98 \pm 0.52$ & $1.88 \pm 0.52$ & 2.085 & $\mathbf{0 . 0 3 8}$ \\
\hline$\underline{\text { INT }}$ & $10.41 \pm 3.53$ & $10.89 \pm 3.55$ & -1.344 & 0.180 & $1.85 \pm 0.53$ & $1.75 \pm 0.57$ & 1.734 & 0.084 \\
\hline$\underline{\text { DEP }}$ & $11.36 \pm 4.21$ & $12.63 \pm 4.3$ & -2.996 & $\mathbf{0 . 0 0 3}$ & $1.66 \pm 0.5$ & $1.54 \pm 0.5$ & 2.531 & $\mathbf{0 . 0 1 2}$ \\
\hline$\underline{\text { ANX }}$ & $10.77 \pm 6.77$ & $8.16 \pm 3.66$ & 4.833 & $\mathbf{0 . 0 0 0}$ & $1.71 \pm 0.53$ & $1.59 \pm 0.45$ & 2.446 & $\mathbf{0 . 0 1 5}$ \\
\hline$\underline{\text { HOS }}$ & $9.67 \pm 3.47$ & $10.25 \pm 3.5$ & -1.668 & 0.096 & $1.66 \pm 0.54$ & $1.51 \pm 0.51$ & 2.768 & $\mathbf{0 . 0 0 6}$ \\
\hline$\underline{\text { PHOB }}$ & $8.38 \pm 7.01$ & $6.34 \pm 2.73$ & 3.878 & $\mathbf{0 . 0 0 0}$ & $1.69 \pm 0.61$ & $1.44 \pm 0.53$ & 4.405 & $\mathbf{0 . 0 0 0}$ \\
\hline$\underline{\text { PAR }}$ & $5.99 \pm 2.23$ & $6.22 \pm 2.19$ & -1.074 & 0.284 & $1.61 \pm 0.46$ & $1.53 \pm 0.44$ & 1.673 & 0.095 \\
\hline$\underline{\text { PSY }}$ & $5.18 \pm 1.9$ & $5.19 \pm 2.03$ & -0.033 & 0.974 & $1.58 \pm 0.44$ & $1.52 \pm 0.41$ & 1.509 & 0.132 \\
\hline
\end{tabular}


Journal of Educational Theory and Management | Volume 04 | Issue 01 | April 2020

Table 4. Comparison of the Average Scores of Each Factor between HTP Test and SCL-90 Test for College Students of Different Genders

\begin{tabular}{|c|c|c|c|c|c|c|c|c|}
\hline \multirow{2}{*}{ Factor } & \multicolumn{4}{|c|}{ HTP test } & \multicolumn{4}{|c|}{ SCL-90 test } \\
\hline & male $(\mathrm{n}=177)$ & female $(n=226)$ & $\mathbf{t}$ & $\mathbf{P}$ & $\operatorname{male}(\mathrm{n}=177)$ & female $(n=226)$ & t & $\mathbf{P}$ \\
\hline$\underline{\text { SOM }}$ & $10.83 \pm 7.64$ & $9.58 \pm 4.35$ & 1.940 & 0.053 & $1.55 \pm 0.5$ & $1.58 \pm 0.42$ & -0.656 & 0.512 \\
\hline$\underline{\mathrm{O}-\mathrm{C}}$ & $7.27 \pm 2.18$ & $7.25 \pm 2.07$ & 0.083 & 0.934 & $1.84 \pm 0.53$ & $2 \pm 0.5$ & -3.160 & 0.002 \\
\hline$\underline{\text { INT }}$ & $10.82 \pm 3.33$ & $10.51 \pm 3.7$ & 0.888 & 0.375 & $1.72 \pm 0.56$ & $1.86 \pm 0.53$ & -2.545 & 0.011 \\
\hline$\underline{\text { DEP }}$ & $12.44 \pm 4.06$ & $11.62 \pm 4.45$ & 1.910 & 0.057 & $1.52 \pm 0.51$ & $1.67 \pm 0.49$ & -2.951 & 0.003 \\
\hline$\underline{\mathrm{ANX}}$ & $10.89 \pm 7.07$ & $8.39 \pm 3.82$ & 4.235 & 0.000 & $1.54 \pm 0.49$ & $1.73 \pm 0.48$ & -3.966 & 0.000 \\
\hline$\underline{\mathrm{HOS}}$ & $9.92 \pm 3.53$ & $9.98 \pm 3.47$ & -0.162 & 0.871 & $1.59 \pm 0.58$ & $1.58 \pm 0.48$ & 0.096 & 0.924 \\
\hline PHOB & $9.3 \pm 7.2$ & $5.87 \pm 2.68$ & 6.015 & 0.000 & $1.37 \pm 0.44$ & $1.73 \pm 0.63$ & -6.877 & 0.000 \\
\hline$\underline{\text { PAR }}$ & $6.19 \pm 2.28$ & $6.03 \pm 2.17$ & 0.725 & 0.469 & $1.55 \pm 0.5$ & $1.59 \pm 0.41$ & -0.864 & 0.388 \\
\hline$\underline{\text { PSY }}$ & $5.63 \pm 2.1$ & $4.83 \pm 1.77$ & 4.152 & 0.000 & $1.51 \pm 0.45$ & $1.58 \pm 0.41$ & -1.594 & 0.112 \\
\hline
\end{tabular}

2.2 Comparison of the Average Scores of HTP Test and SCL-90 Test between College Students of Different Genders

It can be seen from table 4 above that HTP test and SCL-90 test results show that there are significant differences in scores of students of different genders on Anxiety and Phobic Anxiety; SCL-90 test results show that there are significant differences in scores of students of different genders on Obsessive-Compulsive, Interpersonal Sensitivity and Depression, $\mathrm{P}<0.05$; in addition, HTP test results show that there is a significant difference in Psychoticism scores between male and female college students.

\section{Discussion}

(1) By comparing the data and consulting the data, this study found that when carrying out psychological census for college students, some problems need to be paid attention to:1) In the painting, if there are houses without doors and windows, moon, stars, dead trees, fallen leaves, rain and snow, lightning and hail, it is more likely to be related to depression.2) The picture is too small, the picture is located in the lower left corner of the paper, and large area of blackening is often related to inner weakness and anxiety. 3) The picture is too rough, too simple, doors and windows are locked, sharp objects in the painting are more likely to be related to attack and defense. 4) Among the pictures: Nude people, several walls in the same plane, and multiple patterns on the roof are more likely to be related to the psychotic factors. 5) The judgment of painting works must not be mechanically copied. The assessment personnel need to be trained, and it is better to have the relevant experience of painting analysis. 6) Although the painting test cannot be concluded, the risk level can be evaluated according to the number of negative painting features $^{[4-8] \text {. }}$

(2) The HTP test can be used as a supplementary test to the questionnaire test when conducting the psychological survey in Colleges for nationalities. The data of this study also shows that there is a positive correlation between HTP test results and some factor scores of SCL90 test (Table 2, table 3, table 4). This result is similar to the research results of $\mathrm{Li} \mathrm{Na}$, Liu Yan, etc., which shows that the common use of the two tests helps to improve the accuracy of the test.First of all, there are some situations in the questionnaire test, such as students deliberately cover up and answer at random, while the projection test can make up for the deficiency of the questionnaire test to a certain extent, because painting is an artistic language, and the artistic language is neutral, which is not affected by the tendency of social approval, which can well avoid the defensive psychology of the subjects. Second, for the Tibetan college students who are accustomed to speaking Tibetan, some Chinese version of the psychological test questions are really not easy to understand, in addition, due to different national customs and habits, it is easy to lead to test results deviation. HTP test cannot be affected by cultural background and language, so that the subjects can fully express their true self. Third, the way of painting is simple and easy to operate. In addition, painting itself has the function of psychotherapy. Psychotherapy and artistic creation often exist in parallel. Especially in the follow-up interviews, the process of encouraging subjects to explain their paintings is also a kind of therapy ${ }^{[9-11]}$.

(3) Further carry out relevant research and continue to improve the painting evaluation system. Although some scholars call for HTP test to be applied to college census, some experts also point out that painting is a creative 
activity, and any creative activity is conducive to individual growth and mental health. However, HTP has not been widely used, which may be due to the following reasons:1) It is difficult to make quantitative comparison due to the lack of unified scoring standards. 2) It is difficult to score, and lack of relevant professionals. 3) There is no Chinese norm and no comparative data. Therefore, relevant research needs to continue to be carried out to fill the above deficiencies, constantly improve the standard system of painting evaluation, strengthen the training of professional painting analysis personnel, and establish the Chinese data norm and the data norm of all ethnic groups in China ${ }^{[12] .}$

\section{References}

[1] Yan Hu, Chen Jindong. Manual of Painting Analysis and Psychotherapy[M]. Changsha: Central South University Press, 2011, 20-278.

[2] Yan $\mathrm{Hu}$, Huang Fei. Psychological Painting of College Students[M]. Tsinghua University Press, 2019, 60-176.

[3] Yan Hu, Chen Jindong. Handbook of Adolescent Pictorial Psychoanalysis[M]. Changsha: Central South University Press, 2011, 232-346.

[4] Yan $\mathrm{Hu}$, Chen Jindong. Comparison of test results between rural left-behind children and non-leftbehind children[J]. Chinese Journal of Clinical Psychology, 2013, 21(3):417-419.
[5] Yan Hu, Chen Jindong. Use of tree-drawing tests in a group of adolescent depression patients[J]. Chinese Journal of Clinical Psychology, 2012, 20(2):185-187.

[6] Fu Chunshan, Yan Hu. The application of painting psychology in the trial of marriage dispute cases $[\mathrm{J}]$. People's Justice (Application), 2018(25).

[7] Yan Hu, Yang Yi. Application of HTP test in suicide investigation of middle school students[J]. Chinese Journal of Mental Health, 2013(9):650-654.

[8] Yan Hu, Yu Huihui. Application of HTP test in depression investigation of middle school students[J]. Chinese Journal of Clinical Psychology, 2014(5):842848.

[9] Yan $\mathrm{Hu}$, Chen Jindong. Effect and application of painting art therapy in psychotherapy[J]. Chinese Medical Journal of Minkang, 2011(17):2173-2175.

[10] Li Na, Zuo Quanshun. Application of HTP projection test (HTP) in psychological survey of freshmen[J]. Journal of Xingyi Normal University for Nationalities, 2018, 12(6):26-31.

[11] Liu Yan. Evaluation of the application of HTP test in the general survey of recruits' psychological evaluation[J]. South China Journal of National Defense Medicine, 2016(5):331-333.

[12] Zhang Zhe, Hu Yufeng. Art therapy-Understanding the Unknown Self from Painting[M]. Shenyang: Liaoning Education electronic Audio and Video Publishing House, 2017:97-102. 